\title{
A experiência do câncer de mama em palavras: notas sobre as possibilidades emergentes de um corpus temático
}

\author{
Aline Aver Vanin*
}

\begin{abstract}
Resumo
Este texto busca investigar a emergência de metáforas conceptuais no discurso de pacientes de câncer de mama a partir de uma amostra de corpus de textos extraído de depoimentos publicados em blogs. Partese do pressuposto de que o uso de metáforas conceptuais é inerente à comunicação cotidiana, e que tais aspectos são indícios da forma como a cognição humana interpreta o mundo. Para tanto, será tomada como base a arquitetura teórico-metodológica da Linguística Cognitiva a fim de analisar como a expressão da experiência relacionada à doença pode dar indícios sobre a sua verdadeira faceta para cada indivíduo. O trabalho justifica-se por lançar luz à importância da conscientização sobre o discurso ligado a relatos de experiência da expressão de percepções físicas e psíquicas, bem como por abrirem-se possibilidades de elaboração de materiais didáticos e de estratégias de ensino para a formação de profissionais da área da saúde no que diz respeito à atenção em comunicação em saúde.

Palavras-chave: Metáforas conceptuais. Corpus. Câncer de mama. Linguística Cognitiva. Experiência.
\end{abstract}

\section{Introdução}

Compreender os modos de expressão de emoções e sentimentos relacionados a fragilidades em relação a estados de saúde é estabelecer uma relação que vai além da percepção de estado físico do paciente. Os usos de metáforas que se concretizam no discurso de pacientes com câncer de mama podem indicar muito mais do que sintomas da doença em si; de fato, o mapeamento imagético que se faz ao atentar para o discurso da paciente conduz ao mundo subjetivo que emerge em palavras. Tal fato pode ser observado nas pesquisas conduzidas pela equipe de

* Doutora em Linguística (PUCRS). Professora Adjunta do Departamento de Educação e Humanidades da Universidade Federal de Ciências da Saúde de Porto Alegre (UFCSPA). 
Elena Semino, no projeto "Metaphors in the end-of-life care"1 (MELC Project), que demonstram que palavras relativas aos domínios de VIAGEM e de GUERRA são as mais comuns no discurso de pacientes no Reino Unido.

Esta breve pesquisa em blogs brasileiros com testemunhos de pacientes em recuperação de câncer de mama demonstra a emergência de domínios outros, o que corrobora um caráter potencialmente universal, mas também cultural, da metáfora (conforme KÖVECSES, 2002, 2005): na amostra avaliada, as metáforas TER CÂNCER É VIAJAR e TER CÂNCER É LUTAR NUMA GUERRA mostraram-se predominantes. Neste estudo, pretende-se demonstrar, por meio de uma amostra de postagens de blogs pessoais disponíveis na web, além da prevalência do mapeamento com os domínios-alvos VIAGEM e GUERRA, como o discurso de mulheres que sofrem ou que se recuperam da doença aponta para questões que vão além do sofrimento físico, mas principalmente psíquico, o qual dá indícios dos significados construídos pela experiência na e pela carne. Nesse sentido, os propósitos deste texto são (1) analisar brevemente a prevalência de metáforas utilizadas em relatos acerca da vivência com o câncer de mama, e (2) levantar a questão de como a atenção para as ocorrências de metáforas conceptuais no discurso na área da saúde poderia auxiliar nos diagnósticos e no tratamento de pacientes com câncer. Ao final, portanto, pretende-se discutir a relevância da inserção de um debate mais rigoroso acerca da comunicação em saúde na formação de profissionais da área, com especial atenção para o discurso indicativo de elaborações subjacentes aos relatos sobre condições físicas, a fim de contribuir para a formação de profissionais capazes de ouvir e de perceber de modo holístico o sujeito que demanda cuidados.

\section{A emergência de metáforas conceptuais relativas ao câncer}

Exprimir em palavras aquilo que se sente é uma tarefa um tanto quanto árdua quando se tem consciência de que os rótulos linguísticos para determinadas percepções, emoções e sentimentos muitas vezes não alcançam a extensão dos sentidos atribuídos a eles. Nesse sentido, é necessário fazer uso de uma linguagem análoga, repleta de traços concretos, detalhados, para poder expressar aquilo que se sente com maior precisão. Tanto no campo das emoções bem (re)conhecidas da vida cotidiana - como alegria, tristeza, medo -, como em situações cujo

1 Disponível em: <http://ucrel.lancs.ac.uk/melc/index.php>. Acesso em: 1. out. 2016. 
enfrentamento de novas sensações e sentimentos requer uma reelaboração da própria experiência - como em casos mais específicos, em que há o surgimento de alguma patologia, por exemplo -, o discurso metafórico é predominante.

A língua é reflexo daquilo que se passa em nossa realidade subjetiva, e é pela sua concretização, por meio de palavras, que ideias, emoções, percepções são elaboradas. Metáforas são elementos inerentes ao discurso cotidiano, pois fazem parte do nosso sistema conceptual (KÖVECSES, 2002; LAKOFF; JOHNSON, 1980) e, portanto, a sua expressão linguística dá indícios da experiência mais subjetiva. $\mathrm{Na}$ investigação sobre a ocorrência da metáfora conceptual, Lakoff e Johnson (1980) partem de duas teses fundamentais: (i) os conceitos abstratos são amplamente metafóricos, ou seja, o que não faz parte da realidade concreta é conceptualizado na realidade física por meio de domínios da experiência física; (ii) a mente é essencialmente corpórea, o que significa dizer, de modo geral, que os conceitos derivam da experiência sensório-motora. Eles estruturam o que é percebido, como se lida com o mundo e como um indivíduo se relaciona com outras pessoas. Essas construções conceptuais influenciam as experiências e as ações individuais e, ao se estabelecerem na cognição, servirão de base para futuras aplicações linguísticas durante a comunicação.

Falar de nossa subjetividade implica demonstrar como ocorrem os processos de conceptualização baseados em experiências corpóreas (LAKOFF; JOHNSON, 1999) em sentido amplo. Essas emergem de forma esquemática, e são uma forma de organizar o pensamento por meio de mapeamentos entre um domínio mais abstrato e um concreto. Desse modo, se alguém diz que "está sem chão", o que se quer expressar, possivelmente, é toda uma rede de significados envolvidos em um evento de impacto negativo, e a melhor maneira de dizer isso é por meio de um elemento concreto, reconhecido e experienciado por aquele indivíduo. Por isso, assim como "pisar em um terreno firme" pode expressar confiança, "estar sem chão" pode indicar insegurança. O paciente que expressa dor dizendo que sente uma alfinetada em determinada parte do corpo dá indícios da intensidade dessa sensação em determinado órgão. O sujeito que não sabe precisar ao psicólogo como se sentiu ao deparar com uma situação crítica, mas que afirma ter congelado diante de um fato, pode indicar a esse profissional como ele lida com determinadas adversidades da vida.

No âmbito da saúde, metáforas específicas parecem ocorrer a todo o momento. Com frequência, pacientes precisam encontrar maneiras de dizer aquilo que 
sentem de forma clara e precisa, de modo a se fazerem entender por quem os atende; os profissionais da área, por sua vez, precisam encontrar os termos mais específicos e concretos para tornar a informação sobre o estado de saúde desse paciente a mais acurada possível, sem que a escolha de palavras afete ainda mais o estado emocional desse sujeito, já fragilizado.

O surgimento de uma doença, seja qual for, é um evento traumático na vida da maioria das pessoas. Um câncer, por exemplo, pode carregar estigmas e tabus, pois envolve as ideias de dor, abandono e morte, as quais poderão ser enfrentadas no decorrer do tratamento. A expressão das emoções e sentimentos desses pacientes em relação a sua situação pode dar indícios sobre o seu real estado físico, emocional e psíquico. Em outras palavras, o uso dos elementos linguísticos para expressar a percepção sobre sua condição são indícios da sua realidade psíquica, física e emocional.

Dizer que se trava uma "batalha contra o câncer", ou que se deve "permanecer na luta contra" certa doença, ou que alguém é um "sobrevivente" ou se "sucumbe à doença" diz muito sobre a forma como se pensam algumas patologias. Muitas vezes, o foco está apenas na doença, enquanto as percepções desse sujeito doente são deixadas de lado. Susan Sontag, em seus ensaios "Doença como metáfora" e "AIDS e suas metáforas" (1978), demonstra, por uma série de exemplos linguísticos, o modo pelo qual patologias como tuberculose, câncer e AIDS são encaradas em determinadas épocas, e como a forma de fazer referência a elas afeta também o tratamento. No âmbito científico-jornalístico, Paula Span realizou, até 2015, relatos de estudos a respeito do uso de metáforas no domínio da saúde em sua coluna no The New York Times, "The New Old Age: caring and coping". ${ }^{2}$ Para a autora, expressões bélicas refletem sentimentos de negação da morte e também de desafio à morte, evento que é visto em nossa sociedade como um opositor à (ou inimigo da) vida. A mesma autora relata um estudo da Lancaster University, na Inglaterra, em que a linguagem empregada por pacientes, cuidadores e profissionais de saúde é investigada. O projeto de Elena Semino (Lancaster University), "Metaphors in the end-of-life care", já referenciado, investiga o uso de metáforas na experiência do cuidado no fim da vida na GrãBretanha. O grupo de pesquisa de Semino busca fazer uma análise sistemática das metáforas empregadas por membros de grupos diferentes envolvidos nos cuidados em saúde a partir de um corpus de 1,5 milhão de palavras atreladas a entrevistas

2 Disponível em: <http://newoldage.blogs.nytimes.com/>. Acesso em: 22 fev. 2015. 
e contribuições em fóruns online. Desse modo, busca-se corroborar as descrições existentes de teorias sobre metáforas conceptuais como fenômenos linguísticos, cognitivos e sociais.

Nesses trabalhos, verifica-se que as pessoas que trabalham com saúde têm discutido, em interface com a pesquisa linguística, o uso de termos relacionados à imagética da guerra por uma década. Já há uma consciência de que metáforas relacionadas a esse domínio (da GUERRA, da BATALHA) podem ser danosas para os pacientes. Os profissionais, então, são orientados a utilizar expressões linguísticas que suavizam o discurso: em vez de "guerra", usa-se "jornada"; "passos" e "caminhos" são referidos em vez de "armas".

A análise de enunciados como "Sinto que vou poder recomeçar tudo outra vez depois desta doença." pode indicar mapeamentos conceptuais que demonstram a percepção sobre certa patologia, como em:

- A Vida É UMA VIAGEM.

- A doença É uma parada NeSSE PERCURSo.

- A CURA É O REINÍCIO DA VIAGEM.

Nesse sentido, a identificação de tais domínios e de seus mapeamentos (VIDA - VIAGEM; DOENÇA - PARADA; CURA - RECOMEÇO DO PERCURSO) podem sugerir uma visão otimista sobre o tratamento. No entanto, o estudo recente de Semino et al. (2015) contestou os próprios achados quanto ao uso de metáforas que recorrem aos domínios de VIAGEM e de VIOlÊNCIA (ligados ao da GUERRA, por exemplo). Segundo o estudo, realizado por meio da análise textual de depoimentos em blogs a respeito do tema, o uso de metáforas nesses domínios descreve a experiência com a doença, mas itens lexicais relacionados a metáforas de vIOLÊNCIA não necessariamente sugerem sentimentos negativos quanto à doença (como se pode perceber em casos em que as pacientes descrevem a doença como algo que ataca $\mathrm{e}$ que invade seus corpos), e nem sempre expressões ligadas aos domínios de viagem correspondem a emoções positivas (como ocorre em casos em que a paciente se percebe em uma viagem difícil ou como se estivesse percorrendo essa jornada contra sua vontade). Nesse sentido, uma análise apenas das expressões isoladas poderia não revelar os sentidos subjacentes aos textos. Por isso, cabe enfatizar, aqui, que metáforas diferentes podem tratar de um tópico de maneiras diversas, seja enfatizando aspectos ou até mesmo colocando-os em segundo plano, e nem 
sempre uma metáfora possui o mesmo sentido em diferentes contextos de uso.

Numa rápida busca por depoimentos em redes sociais, blogs e fóruns brasileiros ligados à temática do câncer de mama, percebe-se uma riqueza de depoimentos que revelam os modos de expressar emoções e sentimentos ligados a essa doença, bem como demonstram como elementos sociais e culturais podem influenciar na modulação da escolha das metáforas que os expressam. Um exemplo disso é o depoimento de J., ${ }^{3}$ extraído da seção de depoimentos do site do instituto Oncoguia: ${ }^{4}$ “[...] Uma caminhada nada fácil, mas não tão difícil assim que eu não pudesse vencê-la. Vencer talvez não seja o termo exato porque um câncer de mama metastático significa, no meu entendimento, uma doença crônica, que me fará companhia pelo resto da vida, vida essa que poderá acabar dessa doença ou de qualquer outra, amanhã ou daqui há muitos anos. [...] [sic]" (ênfase minha). Neste caso, colocam-se em evidência expressões que dão indícios de como a experiência com a doença é sentida pela paciente em questão: os domínios conceptuais VIAGEM (A DOENÇA É UMA CAMINHADA e A DOENÇA É COMPANHIA NA VIAGEM) e GUERRA (A DOENÇA É UMA BATALHA A SER VENCIDA) saltam aos olhos. Chama a atenção, também, que o cotexto - isto é, o conjunto de sequências linguísticas que precedem ou seguem textualmente determinada palavra ou enunciado - em que a metáfora ligada a GUERRA surge norteia a interpretação para a forma como a paciente percebe a sua experiência, e, caso nos guiássemos pela primeira interpretação do item lexical isolado, poderíamos, certamente, fazer uma interpretação equivocada de todo o restante do relato. Nesse sentido, como será apontado na próxima seção, a análise por concordanciador, ferramenta utilizada em Linguística de Corpus, não poderá levar em conta somente o termo ou a expressão de modos isolados, haja vista que termos colocados, isto é, que coocorrem num mesmo contexto, podem atualizar significados para um mesmo domínio conceptual.

\section{Contexto do estudo, corpus e procedimentos}

Este trabalho é parte da proposta de pesquisa iniciada na Universidade Federal de Ciências da Saúde de Porto Alegre, intitulada "A realização linguística da experiência de mulheres com câncer de mama: um estudo nas áreas de Linguística,

3 Embora disponíveis virtualmente, os dados das depoentes foram omitidos para preservar a sua identidade.

4 Instituto Oncoguia: <http://www.oncoguia.org.br>. Acesso em: 20 fev. 2016. 
Informática e Saúde", que se propõe realizar um trabalho de extração, organização e análise de corpus textual ligado à temática do câncer de mama, a fim de analisar o discurso de elaboração da doença pelas mulheres acometidas por ela em diferentes graus (em tratamento ou em recuperação, por exemplo). Os dados são extraídos do conteúdo disponibilizado pública e virtualmente em redes sociais, fóruns de discussão e blogs sobre o tema, e são organizados por meio de técnicas e recursos computacionais, a partir de ferramentas de mineração de textos (como analisadores automáticos, categorizadores, pré-processadores de textos, taggers, entre outros), de Linguística de Corpus (como concordanciadores) e de técnicas de análise de dados a partir da ótica da Linguística Cognitiva. As técnicas e ferramentas, associadas, podem auxiliar para análise mais acurada de um aspecto não objetivo da linguagem, isto é, de realizações linguísticas de metáforas que são indícios daquilo que se passa no âmbito conceptual. Como já mencionado, empreendimento semelhante é realizado pela equipe de Elena Semino, no MELC Project, que visa justamente chamar a atenção sobre o cuidado do discurso de pacientes com o mesmo tipo de câncer e, ainda, dos profissionais de saúde envolvidos. Tal projeto inspirou a proposta dessa pesquisa para o contexto brasileiro.

O corpus desta pesquisa constitui-se de depoimentos escritos de mulheres que enfrentam ou enfrentaram o câncer de mama, extraídos de blogs pessoais e institucionais, e disponíveis pública e virtualmente. Os dados de cada sujeito foram apagados para preservar as identidades. Para esta análise, foi utilizada uma amostra desse corpus, constituída de 116 depoimentos, aplicada à ferramenta AntConc 3.2.2 (ANTHONY, 2011), ${ }^{5}$ que é capaz de realizar, entre outras ações, a análise de dados textuais a partir da frequência de palavras, da concordância entre elas e da lista de colocados.

Berber Sardinha (2006) chama a atenção para as limitações do uso de listas de palavras e de concordâncias, isoladamente. Para o autor, uma lista de palavras apresenta palavras isoladas, e não permite ao pesquisador ver uma palavra específica em uso, o que é um pré-requisito para a análise de metáforas; já a extração de concordâncias requer que os pesquisadores elaborem que palavras devem buscar, e já que só se pode encontrar aquilo que se procura, e uma decisão errada pode significar que algumas metáforas possam não ser encontradas. Uma lista de colocações, por sua vez, é uma lista de colocados de cada palavra em

5 O AntConc 3.2.2 é um concordanciador de software livre, disponível em: <http://www. laurenceanthony. net/software/antconc/.>. 
um corpus, assim como da concordância entre essas palavras. Uma colocação é a coocorrência de duas ou mais palavras com curto espaço entre elas em um texto (SINCLAIR, 1991). Para este estudo, adota-se uma janela de cinco palavras para a frente ou para trás do termo em foco (ou nodo). Assim, todos os colocados encontrados (isto é, palavras que coocorrem com o nodo), ao serem incorporados no concordanciador, podem ser mostrados em seus contextos originais. Deignan (2005) salienta que colocados frequentes sinalizam uma tensão ou uma incongruência entre uma palavra e seu contexto. A mesma autora, em 2008, afirma que achados em pesquisas na área de Linguística de Corpus indicam que a metáfora linguística é determinada pelo contexto, bem como pelo significado pretendido do falante (ou daquele que escreve) (DEIGNAN, 2008).

Desse modo, no enunciado "[...] pena de todo o mundo que esteja lutando contra o câncer [...]" (grifo meu), extraído do corpus, vê-se o termo em destaque, "lutar", coocorrendo com "câncer", indicando a evidência do uso metafórico desse verbo. No corpus como um todo, esse verbo (algumas vezes substantivado) ocorre 33 vezes e, como ocorreu na pesquisa de Semino et al. (2015), nem sempre ele indica sentimentos negativos quanto à experiência com a doença:

Uma amiga chamada Andrea que conheci tem pouco e lutou bravamente contra a doença e hoje está curada.

(2) Esses não perderam a luta, foram os que lutaram mais bravamente.

Um beijo para todas mulheres guerreiras que estão lutando contra esta doença e que deixam recadinhos tão carinhos e emocionantes aqui.

Peço perdão por às vezes me sentir fraca e peço força para continuar lutando contra esta maldita doença e por tudo que ela me trouxe de ruim.

Nesse caso, LUTAR é o veículo da metáfora, isto é, o foco da metáfora linguística, cuja interpretação seria incongruente no contexto do discurso, ou com o significado criado pelo cotexto (CAMERON, 2003 apud BERBER SARDINHA, 2006). É, também, o domínio-fonte quando se descreve o mapeamento TER CÂNCER É LUTAR NUMA GUERRA.

Dentre os procedimentos de análise adotados para este estudo, ficou 
estabelecido o seguinte:

(1) Uma amostra do corpus de análise, constituída de 116 textos extraídos de blogs relacionados ao tema "câncer de mama", com 7.518 types e 79020 tokens, foi processada pela ferramenta AntConc 3.2.2.

(2) Uma lista de palavras foi gerada conforme a frequência. A partir dela, os principais radicais ligados a verbos foram anotados à parte, bem como substantivos que poderiam ser representativos (como "guerreir*" e "controle"), gerando uma nova lista de análise manual. Stopwords, adjetivos e advérbios foram excluídos dessa lista.

(3) Dessa nova lista, foram observadas as coocorrências entre os nodos e seus colocados.

(4) Dadas incongruências entre nodo e colocado, observou-se o cotexto dessa relação por meio da função "concordance".

(5) Possíveis domínios-fontes, ou veículos, foram anotados (para este e para futuros estudos) e organizados em uma nuvem de palavras.

(6) Metáforas linguísticas e metáforas conceptuais foram anotadas para análise de contextos a partir do concordanciador.

Na próxima seção, far-se-á uma breve análise do corpus, a fim de identificar a prevalência de determinadas metáforas conceptuais na descrição da experiência com o câncer.

\section{0 que os dados mostram}

A partir dos 7.518 types, foi elaborada uma lista de palavras com frequência maior que cinco (5) que conteria potenciais domínios constituintes de mapeamentos metafóricos. É relevante salientar que stopwords (isto é, palavras funcionais como preposições, artigos, conjunções), bem como adjetivos e advérbios, foram excluídos dessa lista. Radicais de verbos (como contin*, *constru*) ${ }^{6}$ e substantivos, com suas variações, foram pesquisados. Dos termos relevantes, temos a seguinte lista:

6 Os asteriscos demonstram que se buscou o radical mais os prefixos e os sufixos possíveis dessas palavras. 
TABELA 1 - Lista de palavras extraída da ferramenta AntConc e pós-processada manualmente após comparação com termos colocados

\begin{tabular}{|c|c|}
\hline VERBOS & Substantivos \\
\hline$*$ constr* & *baix* \\
\hline *caminh* & balanço \\
\hline acompanh* & batalha \\
\hline and* & caminho \\
\hline cheg* & controle \\
\hline come* & guerreira \\
\hline compartilh* & jornada \\
\hline cons*gu* & pesado \\
\hline contin* & cota \\
\hline $\operatorname{cresc}^{*}$ & sobrevivente \\
\hline desenvolv* & suspeit* \\
\hline encar* & viagem \\
\hline encontr* & \\
\hline enfrent* & \\
\hline falt* & \\
\hline lev* & \\
\hline $\operatorname{mud}^{*}$ & \\
\hline olh* & \\
\hline pass* & \\
\hline retorn* & \\
\hline sent* & \\
\hline sinto & \\
\hline vamos & \\
\hline viaj* & \\
\hline zumb* & \\
\hline
\end{tabular}

Fonte: Tabela elaborada pela autora.

Desses termos, constatou-se a coocorrência de vários termos relacionados ao domínio da GUERRA, a partir dos seguintes colocados (e exemplos): 
TABELA 2 - Exemplos de domínios-alvo e seus colocados relacionados ao domínio da GUERRA

\begin{tabular}{|l|l|l|}
\hline \multicolumn{1}{|c|}{$\begin{array}{c}\text { Termo referente ao } \\
\text { domínio-alvo } \\
\text { guerreir* }\end{array}$} & \multicolumn{1}{|c|}{ Colocado } & \multicolumn{1}{c|}{ Exemplo } \\
\hline temos & fui & $\begin{array}{l}\text { "Quem disse que temos } \\
\text { que ser guerreiras?" } \\
\text { "Será que é por que eu } \\
\text { não fui guerreira?" }\end{array}$ \\
\hline $\begin{array}{l}\text { encar* } \\
\text { enfrent* }\end{array}$ & $\begin{array}{l}\text { doença } \\
\text { cirurgia }\end{array}$ & $\begin{array}{l}\text { "Enfrentei a doença, } \\
\text { fiz o tratamento, encarei a } \\
\text { cirurgia," }\end{array}$ \\
\hline olh* & alvo & $\begin{array}{l}\text { "sendo alvo dos olhares } \\
\text { piedosos, curiosos e } \\
\text { maldosos" }\end{array}$ \\
\hline sobrevivente & $\begin{array}{l}\text { começando } \\
\text { última }\end{array}$ & $\begin{array}{l}\text { "Sei que minha batalha } \\
\text { está apenas começando" } \\
\text { "foram comigo para esta } \\
\text { última batalha" } \\
\text { "nunca vou deixar falar } \\
\text { que você perdeu essa } \\
\text { batalha" }\end{array}$ \\
\hline batalha* & $\begin{array}{l}\text { "do tipo 'especial' de } \\
\text { pessoa, você virou 'A' } \\
\text { sobrevivente" }\end{array}$ \\
\hline
\end{tabular}




\begin{tabular}{|c|c|c|}
\hline suspeit* & aparece & $\begin{array}{l}\text { "mama sadia, pois vira } \\
\text { e mexe aparece algo } \\
\text { suspeito" } \\
\text { "quem passou por um } \\
\text { câncer seeeempre vai ficar } \\
\text { apreensiva com qualquer } \\
\text { suspeita" }\end{array}$ \\
\hline lut* & $\begin{array}{l}\text { bravamente } \\
\text { bravamente } \\
\text { doença } \\
\text { doença }\end{array}$ & $\begin{array}{l}\text { "que conheci tem pouco e } \\
\text { lutou bravamente contra a } \\
\text { doença" } \\
\text { "Esses não perderam a } \\
\text { luta, foram os que lutaram } \\
\text { mais bravamente." } \\
\text { "Um beijo para todas } \\
\text { mulheres guerreiras que } \\
\text { estão lutando contra esta } \\
\text { doença" } \\
\text { "peço força para continuar } \\
\text { lutando contra esta maldita } \\
\text { doença" }\end{array}$ \\
\hline
\end{tabular}

Fonte: Tabela elaborada pela autora.

Também foi possível identificar o domínio da VIAGEM, como era previsível, em que as coocorrências com os colocados evidenciavam ainda mais essa relação:

TABELA 3 - Exemplos de domínios-alvo e seus colocados relacionados ao domínio da VIAGEM

\begin{tabular}{|l|l|l|}
\hline $\begin{array}{c}\text { Termo referente ao } \\
\text { domínio-alvo }\end{array}$ & Colocado & Exemplo \\
\hline
\end{tabular}




\begin{tabular}{|c|c|c|}
\hline *aminh* & $\begin{array}{l}\text { passos } \\
\text { tudo } \\
\text { cruzaram }\end{array}$ & $\begin{array}{l}\text { "Fora isso as coisas foram } \\
\text { caminhando a passos } \\
\text { lentos." } \\
\text { "Está tudo caminhando } \\
\text { bem" } \\
\text { "carinho de todos os que } \\
\text { cruzaram seu caminho" } \\
\text { a todos os pacientes que } \\
\text { cruzei pelo caminho" }\end{array}$ \\
\hline acompanh* & todos & $\begin{array}{l}\text { "e a todos que me } \\
\text { acompanharam" }\end{array}$ \\
\hline cheg* & gente & $\begin{array}{l}\text { "tem gente que chega para } \\
\text { ficar" }\end{array}$ \\
\hline contin* & vida & $\begin{array}{l}\text { "e que a vida sempre vai } \\
\text { continuar" } \\
\text { "a vida continua" }\end{array}$ \\
\hline encontr* & mulheres & $\begin{array}{l}\text { "grandes amizades mesmo } \\
\text { com mulheres que se } \\
\text { encontraram em outros } \\
\text { estados" }\end{array}$ \\
\hline lev* & tratamento & $\begin{array}{l}\text { "O que me levou a esse } \\
\text { tratamento?" }\end{array}$ \\
\hline pass* & tudo & $\begin{array}{l}\text { "acaba refletindo sobre } \\
\text { tudo o que passamos" } \\
\text { "fique bem nesse período } \\
\text { passageiro" }\end{array}$ \\
\hline
\end{tabular}




\begin{tabular}{|c|l|l|}
\hline retorn* & doença & $\begin{array}{l}\text { "e não expor para muitos o } \\
\text { retorno da minha doença" }\end{array}$ \\
\hline vamos & lá & "Vamos lá" \\
\hline jornada & nova & $\begin{array}{l}\text { "nessa nova jornada bateu } \\
\text { um frio na barriga" }\end{array}$ \\
\hline super* & escolher & $\begin{array}{l}\text { "podemos escolher se } \\
\text { vamos sofrer, ou enfrentar, } \\
\text { superar" }\end{array}$ \\
\hline balanço & a frente & $\begin{array}{l}\text { "vou deixar esse balanço } \\
\text { mais a frente" }\end{array}$ \\
\hline viagem & $\begin{array}{l}\text { entrar } \\
\text { marinheira }\end{array}$ & $\begin{array}{l}\text { "Eu entrei numa viagem..." } \\
\text { primeira viagem" }\end{array}$ \\
\hline
\end{tabular}

Fonte: Tabela elaborada pela autora.

Além desses, surgiram metáforas que extrapolaram as expectativas, como no domínio da CONSTRUÇão, ao referir-se tanto à reconstituição da mama, após a mastectomia, como ao recomeço da vida:

TABELA 4 - Exemplos de domínios-alvo e seus colocados relacionados aos domínios CONSTRUÇÃO e DESENVOLVIMENTO

\begin{tabular}{|l|l|l}
$\begin{array}{c}\text { Termo referente ao } \\
\text { domínio-alvo }\end{array}$ & Colocado & Exemplo \\
\hline
\end{tabular}




\begin{tabular}{|l|l|l|}
\hline \multirow{2}{*}{$*$ constr* } & $\begin{array}{l}\text { mama } \\
\text { autoestima }\end{array}$ & $\begin{array}{l}\text { "fazendo a reconstrução da } \\
\text { mama este ano" } \\
\text { "processo de reconstrução da } \\
\text { autoestima" }\end{array}$ \\
\hline cresc* & amadureci & $\begin{array}{l}\text { "É... eu cresci, amadureci e } \\
\text { tive um câncer" }\end{array}$ \\
\hline desenvolv* & $\begin{array}{l}\text { "vida tão curto a ponto de } \\
\text { desenvolver essa doença" } \\
\text { câncer }\end{array}$ & $\begin{array}{l}\text { "que um câncer possa ainda } \\
\text { se desenvolver" }\end{array}$ \\
\hline
\end{tabular}

Fonte: Tabela elaborada pela autora.

Metáforas que expressam sentimentos em relação à doença corroboram a hipótese de que o corpo tem um papel crucial no desenvolvimento dos sentidos, como se pode ver abaixo:

TABELA 5 - Exemplos de domínios-alvo e seus colocados relacionados a sentimentos e emoções em relação à doença. Note-se o papel da corporalidade expresso nas palavras.

\begin{tabular}{|l|l|l|}
\hline $\begin{array}{c}\text { Termo referente ao } \\
\text { domínio-alvo }\end{array}$ & \multicolumn{1}{|c|}{ Colocado } & \multicolumn{1}{c|}{ Exemplo } \\
\hline *baix* & $\begin{array}{l}\text { ficasse } \\
\text { vive }\end{array}$ & $\begin{array}{l}\text { "semana para que eu } \\
\text { ficasse um pouco pra } \\
\text { baixo" } \\
\text { "A gente vive em altos e } \\
\text { baixos" }\end{array}$ \\
\hline pesad* & $\begin{array}{l}\text { foi } \\
\text { ano }\end{array}$ & $\begin{array}{l}\text { "Mas ontem foi pesado pra } \\
\text { mim" } \\
\text { "foi um ano tenso, pesado, } \\
\text { mas totalmente suportável" }\end{array}$ \\
\hline
\end{tabular}

Fonte: Tabela elaborada pela autora.

Também é notável a ocorrência de relatos sobre o medo de "perder o controle" diante da doença, em que se compreende que CÂNCER É UMA ENTIDADE A SER CONTROLADA: 
TABELA 6 - Exemplos do domínio-alvo CONTROLE e seus colocados

\begin{tabular}{|l|l|l|}
\hline $\begin{array}{c}\text { Termo referente ao } \\
\text { domínio-alvo }\end{array}$ & \multicolumn{1}{|c|}{ Colocado } & \multicolumn{1}{c|}{ Exemplo } \\
\hline control* & da situação \\
estar no & $\begin{array}{l}\text { "seria porque eu não estaria } \\
\text { no controle da situação" } \\
\text { "de não estar no controle } \\
\text { talvez" }\end{array}$ \\
\hline
\end{tabular}

Fonte: Tabela elaborada pela autora.

Por fim, surgem alguns veículos bastante relevantes, devido a sua ocorrência ser maior de cinco vezes, evidenciando tanto a criatividade na construção de metáforas quanto a sua potencial ligação com a cultura:

TABELA 7 - Exemplos de metáforas criativas

\begin{tabular}{|l|l|l|}
\hline $\begin{array}{c}\text { Termo referente ao } \\
\text { domínio-alvo }\end{array}$ & \multicolumn{1}{|c|}{ Colocado } & Exemplo \\
\hline zumb* & morte & $\begin{array}{l}\text { Logo mais uns 2 meses vem } \\
\text { a revisão novamente... e a } \\
\text { gente vai zumbando com a } \\
\text { morte... }\end{array}$ \\
\hline cota & sofrimento & $\begin{array}{l}\text { "Minha cota de sofrimento } \\
\text { foi de bom tamanho" }\end{array}$ \\
\hline
\end{tabular}

Fonte: Tabela elaborada pela autora.

Nesta breve análise da amostra do corpus, fica evidente a emergência mais frequente de metáforas dos domínios relacionados a GUERRA e a VIAGEM. Ao contrário do que análises isoladas dessas metáforas poderiam sugerir, o exame do contexto demonstrou que nem sempre os relatos que trazem metáforas de GUERRA são negativos (como se pode perceber em "Sei que minha batalha está apenas começando"), como se poderia esperar, nem os depoimentos que trazem metáforas de VIAGEM são sempre positivos ("nessa nova jornada bateu um frio na barriga"). Além disso, o uso da ferramenta AntConc 3.2.2 possibilitou perceber a emergência de expressões bastante criativas, como é o caso de "Logo mais uns 2 meses vem a revisão novamente... e a gente vai zumbando com a morte...". Aqui, pode-se levantar a possibilidade de que a paciente pratique, ou tenha praticado zumba, 
uma modalidade de dança dinâmica, e, para demonstrar a forma como ela enfrenta a possibilidade da morte, cria um neologismo a partir de algo que lhe é familiar.

Na próxima seção, serão feitas considerações sobre a possibilidade de se trabalhar com um corpus com essa temática na formação de profissionais da área da saúde.

\section{Algumas considerações e proposta de trabalhos futuros}

A análise empreendida, ainda que breve e com poucos dados, serve como uma ilustração daquilo que pode ser extraído de textos publicados na rede e pode ser utilizada como material de suporte em disciplinas que abordem a atenção e a comunicação em saúde para a formação de profissionais na área. A motivação de um trabalho sobre o reconhecimento e o uso de metáforas conceptuais nessa área reside na sua utilidade prática para o futuro profissional de saúde, bem como no desejo de uma prática em saúde mais humanizada e ética.

Entende-se que, ao aproximar-se do discurso do paciente, aprofundar a sua escuta e dialogar com ele de forma clara, precisa e humanizada, esse profissional se mune de elementos para poder reconhecer e atuar não apenas sobre a patologia em foco, mas também de forma a olhar o paciente como um sujeito que necessita de amparo não só para a sua saúde física, mas também mental e emocional. Desse modo, pode-se buscar criar rupturas com práticas que não respondem às necessidades contemporâneas da formação do profissional de saúde, isto é, por meio do rompimento com práticas que seguem o modelo biomédico, o qual potencializa o distanciamento de aspectos do cotidiano do trabalho em saúde (TEIXEIRA, 2004). Nesse sentido, o ensino voltado a esse futuro profissional deve levar em conta tanto o seu contínuo processo como aprendiz quanto como indivíduo atuante no mundo do trabalho. As práticas tanto de ensino como de pesquisa devem ter como pressuposto, então, as dimensões do uso da linguagem na área da saúde. Portanto, busca-se, com a observação, a análise e a investigação sobre a língua em seu uso, levar o (futuro) profissional a refletir sobre a sua prática e sobre a sua interação com o paciente não só no plano da linguagem, mas para além da sua arena.

Portanto, para além do trabalho de análise linguística do corpus, um estudo desses dados para uso nas salas de aula de graduação da área da saúde visa, principalmente, à conscientização linguística em relação às metáforas emergentes do discurso de pacientes com enfermidades como o câncer de mama. Metáforas produzidas por essas pacientes podem sugerir momentos de angústia e dor, sentimentos que 
merecem maior atenção pelo fato sabido de que emoções negativas interferem significativamente no sucesso de um tratamento; do mesmo modo, podem indicar o desejo, ou não, de continuar a viver. Assim, um corpus organizado sobre o tema e análises aprofundadas de seu conteúdo podem suscitar atenção e debate sobre os modos de expressar a experiência com a doença entre profissionais da área da saúde, de modo a conscientizá-los sobre os modos de dizer e, principalmente, de ouvir esses pacientes.

Ao aproximar-se do discurso de pacientes e dialogar com eles de forma clara, precisa e humanizada, ele se abastece de elementos para poder reconhecer e atuar não apenas sobre a patologia em foco, mas também de forma a olhar o paciente como um sujeito que necessita de amparo não só para a sua saúde física, mas também mental e emocional. Portanto, a motivação de um trabalho sobre o reconhecimento e o uso de metáforas conceptuais, por meio de um estudo interdisciplinar, reside na sua utilidade prática para os profissionais e futuros profissionais de saúde, bem como no desejo de uma prática em saúde mais humanizada e ética.

\title{
The experience of breast cancer through words: notes on the emerging possibilities from a thematic corpus
}

\begin{abstract}
This text investigates the emergence of conceptual metaphors in the speech of breast cancer patients. The corpus of analysis is constituted of 116 texts extracted from published blogs, available on the web. The use of metaphors is part of daily life communication, and such aspects are hints to the way human cognition interprets the world. Thus, Cognitive Linguistics will be the theoretical basis from which the expression of experience related to the disease may show its real meaning for each individual. This work sheds some light on the importance of the awareness on the discourse related to testimonies on physical and psychical perceptions, as well as opens possibilities on the creation of didactic materials and teaching strategies in the formation of health professionals in the field of communication in health.
\end{abstract}

Keywords: Conceptual metaphors. Corpus. Breast cancer. Cognitive Linguistics. Experience.

\section{Referências}

ANTHONY, Laurence. AntConc (Version 3.2. 2)[Computer Software]. Tokyo, Japan: Waseda University, 2011.

BERBER SARDINHA, Tony. Collocation lists as instruments for metaphor detection in corpora. DELTA, São Paulo, v. 22, n. 2, p. 249-274, 2006.

CAMERON, Lynne; DEIGNAN, Alice. Combining large and small corpora to 
investigate tuning devices around metaphor in spoken discourse. Metaphor and Symbol, v. 18, n. 3, p. 149-160, 2003.

DEIGNAN, Alice. Corpus Linguistics and Metaphor. In: GIBBS, Raymond W. The Cambridge Handbook of Metaphor and Thought. Cambridge: Cambridge University Press, 2008. p. 280-294.

DEIGNAN, Alice. Metaphor and Corpus Linguistics. Amsterdam/Philadelphia: John Benjamins, 2005.

KÖVECSES, Zoltán. Metaphor: a practical introduction. New York: Oxford University Press, 2002.

KÖVECSES, Zoltán. Metaphor in culture: universality and variation. Cambridge: Cambridge University Press, 2005.

LAKOFF, George; JOHNSON, Mark. Metaphors We Live By. Chicago: The University of Chicago Press, 1980.

LAKOFF, George; JOHNSON, Mark. Philosophy in the flesh: the embodied mind and its challenge to western thought. New York: Basic Books, 1999.

SEMINO, Elena et al. Metaphor in the end-of-life care (MELC). Disponível em: $<$ http://ucrel.lancs.ac.uk/melc/index.php>. Acesso em: 1. out. 2016.

SEMINO, Elena; DEMJÉN, Zsofia; DEMMEN, Jane; KOLLER, Veronika; PAYNE, Sheila; HARDIE, Andrew; RAYSON, Paul. The online use of Violence and Journey metaphors by patients with cancer, as compared with health professionals: a mixed methods study. BMJ Supportive \& Palliative Care, 2015.

SINCLAIR, John. Corpus, concordance, collocation. Oxford: Oxford University Press, 1991.

SONTAG, Susan. Doença como metáfora: AIDS e suas metáforas. São Paulo: Companhia de Bolso, 1978.

SPAN, Paula. Fighting words are rarer among British doctors. The New York Times. Disponível em: <http://newoldage.blogs.nytimes.com/2014/04/22/ fighting-words-are-rare-among-british-doctors/?_php=true\&_type=blogs\&_ $r=0>$. Acesso em: 1. out. 2016.

SPAN, Paula. Wounded by the language of war. The New York Times. Disponível em: $\quad<$ http://newoldage.blogs.nytimes.com/2014/04/11/wounded-by-thelanguage-of-war/>. Acesso em: 1. out. 2016.

TEIXEIRA, José A. Carvalho. Comunicação em saúde: relação técnicos de saúdeutentes. Aná. Psicológica, Lisboa, v. 22, n. 3, p. 615-620, set. 2004.

Recebido em 10/04/2016. Aceito em 05/07/2016. 